\title{
Diaphragm Fluoroscopy
}

National Cancer Institute

\section{Source}

National Cancer Institute. Diaphragm Fluoroscopy. NCI Thesaurus. Code C159678.

A fluoroscopic medical test done to evaluate the function of the diaphragm. The subject

is asked to sniff quickly and the movement of the diaphrag $\mathrm{m}$ is monitored with a

fluoroscope. It is a quick and easy real-time assessment of diaphragmatic motor

function. 